\title{
Субпопуляции В-лимфоцитов и влияние микроокружения на их функциональную активность
}

\author{
Лаборатория биосинтеза иммуноглобулинов УРАМН "НИИ вакцин и сывороток им. И.И.Мечникова РАМН": 105064, Москва, Малый Казенный пер., $5 \mathrm{a}$
}

\section{I.N.Dyakov, E.V.Sidorova \\ B-lymphocyte subpopulations: microenvironmental nfluence on functional activity}

Key words: B-lymphocytes, B1 cells, B2 cells, abdomen, spleen, microenvironment, mucus defense, functional activity, immunoglobulin synthesis. Ключевые слова: В-лимфоциты, В-1-клетки, В-2-клетки, брюшная полость, селезенка, микроокружение, зашита слизистых оболочек, функциональная активность В-клеток, синтез иммуноглобулинов.

Около 150 лет назад в крови людей и животных были обнаружены так называемые красные и белые "кровяные шарики". Красные шарики получили название "эритроциты", а белые - "лейкоциты". Впоследствии лейкоциты стали подразделять на собственно лейкоциты и лимфоциты. Лимфоциты привлекли основное внимание исследователей, поскольку довольно рано было установлено, что именно они являются продуцентами антител. В 70-х гг. ХХ в. стало известно, что лимфоциты неоднородны. Предшественники одних лимфоцитов рано покидают костный мозг и продолжают свое развитие в тимусе - впоследствии они получили наименование "Т-лимфоциты". Другие лимфоидные клетки, дифференцирующиеся у млекопитающих в костном мозгу, а у птиц - в Фабрициевой сумке (Bursa Fabrizius), названы "В-лимфоцитами" (т. е. Bursa-зависимыми).

В-лимфоциты - важнейший компонент иммунной системы. Их основная функция - образование антител к разнообразным эндогенным и экзогенным антигенам [1]. Кроме того, они участвуют в различных межклеточных взаимодействиях: в презентации антигена, регуляции активности Т-лимфоцитов и формировании структуры вторичных лимфоидных органов. В настоящее время выделяют 4 основные субпопуляции В-лимфоцитов, различающиеся по своим свойствам и локализации: В-1a, B-1b, В-2 и В-клетки маргинальной зоны (MZ-B) [2].

В-клетки разных субпопуляций обладают неодинаковыми свойствами и выполняют разные функции в иммунной защите организма от патогенов. Так, В-1-лимфоциты реагируют преимущественно на аутоантигены и бактериальные антигены, также они участвуют в формировании мукозального иммунитета, обеспечивающего защиту слизистых оболочек респираторного и пищеварительного трактов. MZ-B предохраняют организм от бактериальных антигенов, попавших в кровь. В-2-лимфоциты являются главными игроками на поле адаптивного иммунного ответа и вносят основной вклад в элиминацию чужеродных антигенов из организма.
В-клетки распределены в организме неравномерно. Так, в селезенке преобладают лимфоциты В-2, а в брюшной полости - B-1. Долгое время считалось, что дифференциация свойств В-клеток разной локализации обусловлена преобладанием тех или иных субпопуляций. Однако в последнее 10-летие появились данные о том, что свойства В-лимфоцитов одной субпопуляции зависят от их локализации.

Рассмотрим более детально основные сходства и различия В-лимфоцитов, принадлежащих к разным субпопуляциям.

\section{Свойства субпопуляций В-лимфоцитов}

Все В-лимфоциты обладают рядом общих свойств: они продуцируют антитела и иммуноглобулин (Ig), экспрессируют антиген-распознающий Ig-рецептор (B-Cell Receptor - BCR) и поверхностные маркеры CD19 и CD45 (B220). Вместе с тем можно выделить несколько субпопуляций В-клеток, различающихся по происхождению, дифференцировке, фенотипу и функциональным свойствам. Подавляющее большинство В-лимфоцитов во взрослом организме мыши и человека составляют В-2-клетки. Именно их принято называть собственно В-лимфоцитами. В-1 и MZ-B представляют собой минорные субпопуляции.

В 1982-1983 гг. были найдены В-клетки, несущие поверхностный маркер Т-лимфоцитов CD5 [3, 4]. Эти клетки значительно отличались от "обычных" В-лимфоцитов как по фенотипу, так и по распределению в организме и функциональным свойствам. Первоначально $\mathrm{CD}^{+}$B-лимфоциты были описаны у людей как патологические В-клетки [5-7, 4]. Однако впоследствии было выяснено, что такие клетки есть и у нормальных животных, и человека [8]. Поскольку В-клетки $\mathrm{CD}^{+}$появляются в онтогенезе раньше CD5-, A.Kantor et al. в 1991 г. предложили новую номенкулатуру, согласно которой $\mathrm{CD}^{+}$получили название "B-1", а "обычные" В-клетки CD5- "B-2" [9]. Несколько позднее были обнаружены клет- 

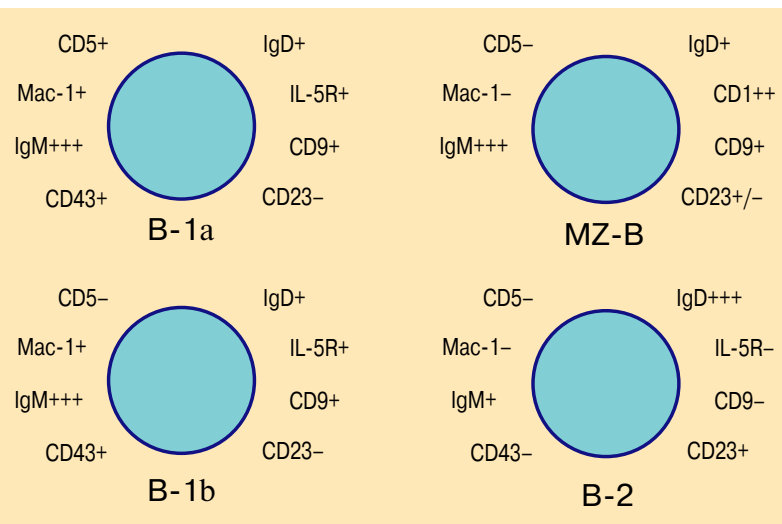

Рис. 1. Субпопуляции В лимфоцитов

ки, по своим свойствам сходные с $\mathrm{CD}^{+}$, но не несущие поверхностного маркера CD5. Это привело к подразделению В-1-лимфоцитов на $\mathrm{CD}^{+}$B-1а и "сестринскую" субпопуляцию CD5- B-1b [10]. Затем была открыта еще одна субпопуляция, сходная как с В-1-, так и с В-2-лимфоцитами, - MZ-B. Таким образом, в настоящее время выделяют 4 основные субпопуляции В-клеток: В-1a, В-1b, В-2 и MZ-B (рис. 1).

Следует, однако, оговориться, что такой "набор" субпопуляций характерен для линейных мышей и человека, у других животных он несколько иной. Так, у кроликов все В-клетки несут маркер CD5 [11], а у крыс все В-1-лимфоциты являются CD5-. В 2007 г. группа французских ученых выявила у мышей "дикого типа" (wild-type) В-лимфоциты, отличающиеся по своим свойствам от В-клеток всех известных субпопуляций. Такие клетки были названы Вw-лимфоцитами (от $B$-wild). В незначительном количестве они есть и у мышей чистых линий [12]. Однако недостаточная изученность свойств Bw-клеток и неоднородность мышей "дикого" типа пока не позволяют утверждать, что речь идет о действительно новой субпопуляции В-лимфоцитов.

Длительное время вопрос о происхождении субпопуляций В-клеток являлся предметом ожесточенных споров. Существовали 2 основные гипотезы: линейная и активационная. Согласно линейной гипотезе, лимфоциты В-1 и В-2 происходят от разных предшественников. Эта гипотеза основывалась на данных по переносу клеток фетальной печени и костного мозга нормальных мышей облученным и scid (severe combined immunodeficiency) мышам, у которых отсутствуют собственные В-клетки. В этих работах было показано, что большинство фетальных про-Вклеток давали начало лимфоцитам В-1, а большинство костномозговых про-В-лимфоцитов - В-2. Эту гипотезу подтверждали и данные о существовенных различиях в свойствах В-1 и В-2 [13, 14, 2]. Активационная гипотеза, напротив, предполагала происхождение В-клеток от одного предшественника, развившегося в B-1- или В-2-клетки в зависимости от специфичности BCR, их плотности и силы поступающего сигнала. В пользу этой гипотезы свидетельствовало приобретение в определенных случаях активированными В-2-лимфоцитами поверхностного антигена CD5, а также некоторых черт В-1-клеток $[15,16]$.
Споры вокруг этих гипотез продолжались вплоть до 2006 г., когда этот вопрос был, наконец, решен. В Nature Immunology появилась статья E.MontechinoRodrigues et al. [17], в которой было показано наличие ранних специфических предшественников В-1-клеток, отличавшихся от таковых у В-2-лимфоцитов. Это подтверждало, что В-1 и В-2 происходят от разных предшественников. Однако, по-видимому, в зависимости от специфичности BCR фенотип и функциональные особенности В-лимфоцитов могут отличаться от "стандартных" для данной субпопуляции.

Как уже говорилось, в онтогенезе у мыши и человека первыми появляются $\mathrm{CD}^{+}$B-1-лимфоциты. Раньше всего они обнаруживаются в желточном мешке и оментуме, а затем в эмбриональной печени. После рождения предшественники В-1 мигрируют в основном в перитонеальную полость, где существуют как самоподдерживающиеся клетки. Ранее считалось, что источником всех $\mathrm{CD}^{+} \mathrm{B}-1-$ клеток являются именно перитонеальные В-1-лимфоциты, однако постепенно накопилось много исключений из этого "правила". Так, оказалось, что, по крайней мере, часть CD5- B-1b-клеток может происходить от предшественников, находящихся во взрослом костном мозге [18]. В последние годы были опубликованы работы, данные которых позволяют предположить, что не только $\mathrm{CD}^{-} \mathrm{B}-1 \mathrm{~b}-$, но и $\mathrm{CD}^{+}$ B-1а- лимфоциты могут образовываться во взрослом организме de novo. Так, в оментуме (сальнике) взрослых мышей были обнаружены клетки-предшественники В-лимфоцитов, сходные с предшественниками из фетальной печени [19]. Появились также данные о том, что В-лимфоциты $\mathrm{CD}^{+}$могут развиваться во взрослом костном мозге [20, 21]. Однако последнее утверждение нуждается в проверке.

Предшественники В-2-лимфоцитов в онтогенезе также выявляются сначала в эмбриональной печени (но позже, чем предшественники В-1), откуда они мигрируют в костный мозг. Образование новых В-2лимфоцитов в зрелом костном мозге происходит постоянно в течение всей жизни организма.

Вопрос о происхождении лимфоцитов MZ-B в настоящее время до конца не решен. Эти клетки появляются уже после рождения: у грызунов - на 3-4-й нед. [22, 23]. Некоторые исследователи считают, что в маргинальной зоне селезенки содержатся самоподдерживающиеся предшественники лимфоцитов MZ-B [24]. Согласно другой точке зрения, они происходят из предшественников в костном мозге, сходных с таковыми для В-2 клеток [23]. И наконец, существует предположение, согласно которому MZ-B способны развиваться как из предшественников В-2, так и из предшественников В-1 [25].

Как уже упоминалось, большинство В-клеток в организме человека и мыши представлено В-2лимфоцитами. Типичные особенности этой субпопуляции изучены наиболее полно. Представляется интересным сравнить свойства клеток В-1 и В-2.

У взрослых мышей и человека В-2-клетки локализованы в основном в селезенке, крови, лимфатических 
узлах, Пейеровых бляшках, отдельных фолликулах лимфоидной ткани кишечника, костном мозге и брюшной полости. В-1-клетки, напротив, выявляют преимущественно в перитонеальной полости и lamina propria кишечника, кроме того, они содержатся в селезенке и плевральной полости; единичные В-1 обнаруживают в костном мозге. У человека лимфоциты B-1 присутствуют в лимфатических узлах, у мышей их выявить там не удается. MZ-B у мышей заселяют только маргинальную зону селезенки (что отражено в их названии), у человека эти клетки присутствуют также в маргинальной зоне лимфатичеких узлов.

В-лимфоциты разных субпопуляций имеют четкие фенотипические и функциональные различия (таблица). В-2 являются $\operatorname{IgM}^{\text {low }}, \operatorname{IgD}^{\text {high }}, B^{2} 20^{\text {high }}$, $\mathrm{CD}^{2}{ }^{+}, \mathrm{CD}^{4}{ }^{-}, \mathrm{CD}^{-}$, тогда как фенотип B-1 лимфоцитов - $\mathrm{IgM}^{\text {high }}, \mathrm{IgD}^{\text {low }}, \mathrm{B} 220^{\text {low }}, \mathrm{CD} 23^{\text {low/-}}, \mathrm{CD}^{+} 3^{+}$ (high - высокая экспрессия, low - низкая экспрессия, ${ }^{+}$- маркер экспрессируется, ${ }^{-}-$экспрессия отсутствует). Клетки В-1а, как уже было сказано, эспрессируют CD5, а B-1b являются лимфоцитами CD5-. Для B-1-клеток характерен также активированный фенотип, в частности повышенная экспрессия активационных молекул CD80 / CD86, что может свидетельствовать о предшествовавшем антигеном опыте.

Подавляющее большинство В-2-клеток отвечает на белковые (тимус-зависимые - Т3) антигены. После активации антигеном В-2 клетки мигрируют в зародышевые центры фолликулов, где претерпевают смену изотипа и проходят этап созревания аффинности секретируемых антител. Для успешного прохождения этих этапов В-2-клеткам необходима специфическая помощь Т-лимфоцитов (Т-хелперов).

Таблица

Сравнительная характеристика В-1, MZ-B и фолликулярных В-2-клеток

\begin{tabular}{|c|c|c|c|}
\hline Характеристика & B-1 & MZ-B & B-2 \\
\hline Период полуобмена & Длительный & Длительный & Длительный \\
\hline Рециркуляция в лимфе & - & - & + \\
\hline Т-независимый ответ & +++ & +++ & + \\
\hline Т-зависимый ответ & $+/-?$ & + & + \\
\hline $\begin{array}{l}\text { Преимущественные } \\
\text { изотипы }\end{array}$ & $\lg M, \lg G 3$ & $\lg M, \lg G 3$ & $\lg G 1$ \\
\hline $\begin{array}{l}\text { Презентация антигена } \\
\text { in vitro }\end{array}$ & +++ & +++ & + \\
\hline Клеточный цикл & Короткий & Короткий & Длинный \\
\hline \multicolumn{4}{|l|}{ Пролиферация в ответ на: } \\
\hline липополисахарид & +++ & +++ & + \\
\hline анти-CD40 & ++ & ++ & + \\
\hline анти-IgM & - & - & + \\
\hline анти-IgM + анти-CD40 & t+ & ++ & t+ \\
\hline Экспрессия CD9 & + & ++ & $+1-$ \\
\hline $\begin{array}{l}\text { Апоптоз, индуцированный } \\
\text { анти-IgM }\end{array}$ & - & & + \\
\hline $\begin{array}{l}\text { Экспрессия маркеров } \\
\text { B-1-клеток (CD5, IL-5R, } \\
\text { CD43) }\end{array}$ & + & & - \\
\hline $\begin{array}{l}\text { Устойчивость к Fas-опосре- } \\
\text { дованному апоптозу }\end{array}$ & + & & - \\
\hline
\end{tabular}

В зародышевых центрах В-2 дифференцируются в плазматические клетки, продуцирующие высокоаффинные специфичные антитела, преимущественно изотипа $\operatorname{IgG}$ (но также $\operatorname{IgA}$ и $\operatorname{IgE}$ ), а также в долгоживущие клетки памяти. На способности В-2-лимфоцитов дифференцироваться в клетки памяти основано действие большинства вакцин. Однако, несмотря на высокую эффективность, ТЗ-ответ имеет один существенный недостаток: для его достижения требуется длительное время (несколько суток).

В отличие от В-2-лимфоцитов, В-1-клетки отвечают в основном на тимус-независимые антигены 1-го и 2-го рода (Th1 и Th2 соответственно). K Th1антигенам относят липополисахариды, обладающие выраженным митогенным действием. К Th2 принадлежат небелковые антигены - преимущественно полисахариды клеточных стенок бактерий, синтетические антигены и др. Такие антигены не вовлекают в специфический иммунный ответ Т-хелперы. В ответ на Th2-антигены В-1-лимфоциты продуцируют преимущественно низкоаффинные, часто полиреактивные, IgM-антитела и не формируют В-клеток памяти. Однако лимфоциты В-1 начинают продуцировать антитела сразу после активации, не проходя сложных этапов формирования зародышевых центров. Благодаря этому они защищают организм от патогена до развития высокоспецифичного ответа В-2клеток, формируя 1-ю линию защиты. Кроме того, B-1-лимфоциты продуцируют полиреактивные IgMантитела конститутивно (без антигенной стимуляции). Важно отметить, что В-1 клетки продуцируют $>50 \%$ нормального IgM крови. По-видимому, это в основном функция клеток $\mathrm{CD}^{+} \mathrm{B}-1 \mathrm{a}$, тогда как лимфоциты CD5- B-1b отвечают преимущественно по адоптивному типу.

Около 50 \% IgA-продуцентов кишечника происходят из В-1-лимфоцитов брюшной полости. IgA играют роль в защите слизистых оболочек, которые одними из первых встречаются с патогенами ("входные ворота" инфекции). Образование В-1-клетками IgA удивительно, поскольку эти клетки "работают" в отсутствие Т-клеточной помощи, необходимой для переключения синтеза с $\operatorname{Ig}$ М на $\operatorname{IgA}$, и непонятно, каким образом происходит переключение с IgM на IgA без участия Т-хелперов. Возможно, в этом участвуют $\gamma \delta$ Т-клетки слизистых оболочек [26-28].

Следует упомянуть, что В-1-лимфоциты не только выполняют защитную функцию, но и могут быть причиной развития патологии. Среди перитонеальных В-1-клеток выявлены аутореактивные клоны, участвующие в развитии аутоиммунных заболеваний. В 95 \% случаев хронического лимфолейкоза источником раковых B-CLL клеток являются B-1-лимфоциты $\mathrm{CD}^{+}$.

Помимо В-1, к В-клеткам, формирующим 1-ю линию защиты, относят MZ-B. По экспрессии маркеров MZ-B лимфоциты сходны с B-2 - IgM $^{\text {high }}$, $\mathrm{IgD}^{\text {low }}, \mathrm{CD}^{2} 3^{\text {high }}, \mathrm{CD}^{-}$, в то же время отличаясь от них повышенной экспрессией CD9, CD21 и CD1d. MZ-B отвечают преимущественно на полисахаридные бактериальные антигены, попавшие в кровь 
(blood-borne). Этому способствует повышенная экспрессия маркера CD21, связывающего комплексы комплемента с полисахаридными антигенами [29]. MZ-B, как и B-1, участвуют в формировании пула нормальных $\operatorname{IgM~крови.~В~определенных~условиях~}$ MZ-B способны образовывать клетки памяти.

Таким образом, свойства В-клеток различных субпопуляций неодинаковы. Однако и свойства В-лимфоцитов, принадлежащих к одной субпопуляции, могут варьироваться также в зависимости от локализации В-клеток.

\section{Свойства В-клеток разной локализации}

Лучше всего изучены свойства В-клеток селезенки и брюшной полости. Как уже говорилось, долгое время В-клетки селезенки ассоциировались с субпопуляцией В-2, а В-клетки брюшной полости - c B-1, поэтому различия спленоцитов В-2 и перитонеальных клеток В-1 описывали как характерные для той или иной субпопуляции в целом.

Оказалось, однако, что свойства В-лимфоцитов одной и той же субпопуляции, локализованных в разных органах, неодинаковы. В частности, В-клетки разной локализации отличаются экспрессией поверхностных и внутриклеточных маркеров. Подавляющее большинство В-лимфоцитов брюшной полости (как В-1, так и В-2) экспрессируют макрофагальный маркер Мас-1 (CD11b), в то время как В-клетки селезенки являются Мас-1- [30]. Известно, что, покидая брюшную полость и мигрируя в селезенку, В-лимфоциты перестают экспрессировать Мас-1. С выявлением экспрессии Мас-1 на перитонеальных В-лимфоцитах связано одно из недоразумений в иммунологии: в 2006 г. Rothstein et al. обнаружили в брюшной полости мышей В-лимфоциты $\mathrm{CD}^{+}$ Mac-1- и обозначили эти клетки как B-1c [31]. Однако уже на следующий год Herzenberg et al. показали, что это всего лишь одна из стадий развития перитонеальных В-1-лимфоцитов. Показано, что перитонеальные В-1а-клетки несут больше CD80 (B7.1) и IgM, чем спленоциты В-1a [32, 33]. В-1-лимфоциты селезенки и брюшной полости различаются также по экспрессии других молекул, определяющих их функциональную активность: факторов транскрипции, молекул адгезии и др. [34-37]. Однако чем обусловлена избирательная экспрессия тех или иных молекул, пока неизвестно.

Содержание В-клеток, обладающих одной и той же специфичностью, в разных органах неодинаково. Например, в брюшой полости у мышей частота B-1а-клеток, специфичных к фосфатидилхолину (входит в состав клеточных оболочек бактерий и выявляется на собственных стареющих эритроцитах), в 60-70 раз превышает таковую в селезенке [33]. В то же время в селезенке содержание В-1а-клеток, специфичных к 1-цепочечной ДНК, выше, чем в брюшной полости. Кроме того, разнообразие CDR3 (Complementary Determining Region) участков генов иммуноглобулинов у В-1а-клеток селезенки выше, чем среди перитонеальных В-1а-лимфоцитов.
В-клетки разной локализации существенно различаются также и по способности отвечать на активационные сигналы, поступающие через BCR. Так,

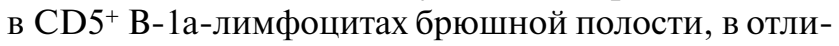
чие от аналогичных клеток селезенки, при перекрестном связывании BCR не происходит повышения внутриклеточной концентрации $\mathrm{Ca}^{2+}$ - процесса, характерного для активации. Перитонеальные В-1лимфоциты входят в клеточный цикл в ответ на действие 1 форболового эфира, а В-1-клетки селезенки - только в присутствии иономицина (ионофора, осуществляющего транспорт ионов $\mathrm{Ca}^{2+}$ ). В-2лимфоциты селезенки не отвечают на форболовый эфир без иономицина, но начинают пролиферировать в ответ на перекрестное связывание BCR.

Таким образом, перитонеальные В-1-лимфоциты проявляют свойства, характерные для клеток в состоянии анергии, а В-1-клетки селезенки нет [2, 14].

Наиболее важная особенность В-лимфоцитов брюшной полости - неспособность продуцировать Ig in vivo. Однако перитонеальные В-клетки при адаптивном переносе начинают синтезировать / секретировать Ig в селезенке реципиентов (в другом микроокружении) [32, 38-40]. Аналогичный эффект достигается также при инкубации перитонеальных В-лимфоцитов in vitro [33, 41]. Учитывая постоянную рециркуляцию В-лимфоцитов в организме, можно заключить, что эта особенность В-клеток брюшной полости обусловлена действием перитонеального микроокружения.

При этом неизвестно, чем объясняется отсутствие образования Ig в брюшной полости - запретом на активацию перитонеальных В клеток или на синтез / секрецию Ig. Для ответа на этот вопрос был проведен ряд экспериментов по адоптивному переносу спленоцитов и перитонеальных клеток мышей CBA-мышам конгенной линии CBA/N с последующим определением функциональной активности перенесенных клеток по числу IgM-продуцентов в селезенке и брюшной полости реципиентов [39, 40]. Мыши CBA/N несут xid-мутацию в гене тирозинкиназы Брутона (Btk) - фермента, участвующего в трансдукции сигнала. У них резко снижено число клеток (как общее, так и В-лимфоцитов) в селезенке и брюшной полости, также у них отсутствуют $\mathrm{CD}^{+}$ В-1а-клетки, в связи с чем они не отвечают на Th2антигены.

Внутривенное введение спленоцитов СВА, содержащих Ig-продуценты, вызывало увеличение числа IgM-продуцентов в селезенке мышей CBA/N. При введении спленоцитов внутрибрюшинно IgMпродуценты в перитонеальной полости реципиентов не выявлялись. Чтобы исключить влияние чужого микроокружения (брюшная полость) для Ig-продуцентов, переносимых из селезенки, были проведены эксперименты по внутрибрюшинному переносу перитонеальных клеток. Поскольку В-клетки, выделенные из брюшной полости, не продуцируют Ig, их предварительно вносили в систему in vitro и инкубировали без какой-либо стимуляции антигенами или 
митогенами. Это приводило к появлению 4 0006500 IgM-продуцентов на $10^{6}$ клеток (vs 0-50 IgMобразующих клеток в исходной суспензии клеток) (рис. 2А). Такие "активированные" перитонеальные клетки переносили внутрибрюшинно мышам CBA/N и на 4-е сут. определяли число $\operatorname{IgM-продуцентов~}$ в брюшной полости реципиентов. На 1-е сут. в ней выявлялось $30 \%$ от количества перенесенных IgMпродуцентов (рис. 2B), однако на 4-е сут. IgM-продуценты из брюшной полости вновь исчезали (т. е. восстанавливалась обычная картина; рис. 2В). На 4-е сутки после переноса (т. е. после исчезновения IgMпродуцентов) перитонеальные клетки реципиентов CBA/N помещали in vitro и инкубировали в течение 4 сут. После инкубации в суспензии клеток вновь появлялись $\operatorname{Ig}$ М-продуценты, причем их число соответствовало выявляемому на 1-е сут. после переноса (рис. 2Г). Важно, что IgM-продуценты, выявляемые при такой "повторной" инкубации in vitro, обусловлены перенесенными клетками, поскольку перитонеальные клетки мышей CBA/N после инкубации in vitro практически не содержали IgM-продуцентов (рис. 2Д).

Таким образом, с использованием разработанной оригинальной схемы "обратного" переноса клеток in vitro - in vivo - in vitro [39] удалось показать, что прежде введенные IgM-продуценты не погибают и не уходят из перитонеальной полости, но "замолкают" (перестают синтезировать / секретировать IgM) под действием перитонеального микроокружения. Следует отметить, что полученные данные не являлись результатом кардинального изменения свойств В-клеток, вызванных культивированием их in vitro, поскольку внутрибрюшинный перенос мышам CBA/N преинкубированных in vitro спленоцитов мышей СВА к появлению IgM-продуцентов в брюшной полости не приводил.

Механизмы угнетения синтеза / секреции Ig В-лимфоцитами в брюшной полости в настоящее время неизвестны. Возможно, в этом процессе могут быть задействованы факторы, продуцируемые активированными перитонеальными макрофагами: простагландин Е2 и ганглиозиды (сиалогликосфин-

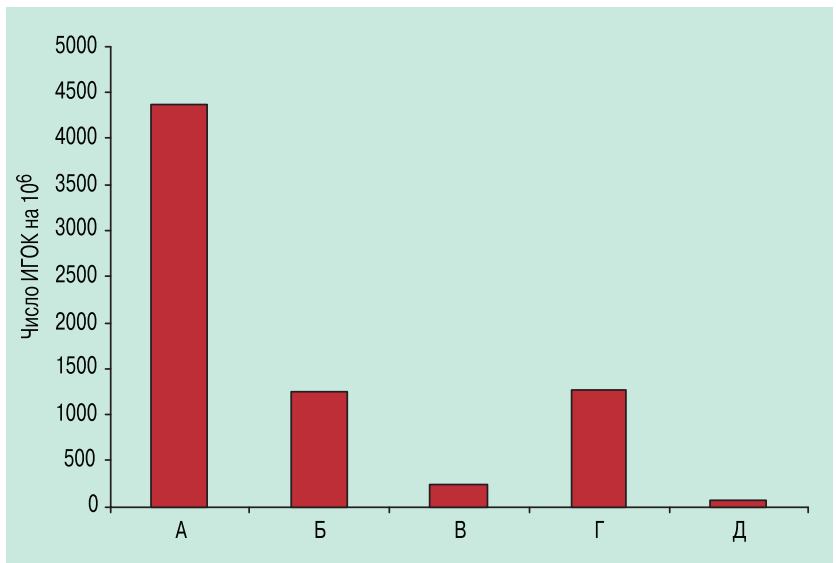

Рис. 2. Число Ig-образующих клеток (ИГОК) в брюшной полости мышей $\mathrm{CBA} / \mathrm{N}$, получивших преинкубированные перитонеальные клетки мышей СВА (пояснение в тексте) голипиды) [42, 43] или постоянное воздействие на В-лимфоциты антигенов, присутствующих в брюшной полости [32]. На функциональную активность В-лимфоцитов могут также влиять мезотелиальные перитонеальные клетки, вносящие существенный вклад в формирование цитокинового профиля брюшной полости [44], а также интерлейкин-10 (важный иммуносупрессорный цитокин), конститутивно секретируемый перитонеальными В-1-лимфоцитами [45].

Значение угнетения функциональной активности перитонеальных В-клеток тоже не вполне ясно. Поскольку многие из преобладающих в брюшной полости В-1-лимфоцитов специфичны к аутоантигенам, можно предположить, что подавление активности В-клеток в брюшной полости связано с защитой организма от аутоагрессии, а все остальные В-клетки просто попадают под действие общего "запрета". Далее перитонеальная полость коммитирует В-лимфоциты к миграции в лимфоидную ткань кишечника, при этом у клеток изменяется экспрессия ряда маркеров. Угнетение функциональной активности также может быть связано с этим процессом. Кроме того, пул лимфоцитов В-1, по крайней мере частично, восстанавливается за счет самоподдерживающихся клеток в брюшной полости. В связи с этим можно предположить, что микроокружение перитонеальной полости поддерживает деление и дифференцировку В-клеток, но угнетает их функциональную активность. Однако это предположение требует проверки.

Интересно, что В-лимфоциты брюшной полости имеют активированный фенотип, но при этом их функциональная активность угнетена, т. е. они поддерживаются как бы в "законсервированном" состоянии. Вместе с тем, как уже упоминалось, В-клетки брюшной полости вносят существенный вклад в функционирование лимфоидной ткани слизистой оболочки кишечника. В связи с этим подавление активности В-лимфоцитов в брюшной полости, непосредственно граничащей с кишечником, кажется еще более непонятным и удивительным. Влияние микроокружения брюшной полости на активность В-лимфоцитов - важная проблема фундаментальной иммунологии, требующая дальнейшего изучения.

\section{Иммунная защита слизистых оболочек}

В последнее время актуальным стало изучение лимфоидной ткани слизистых оболочек (mucosa associated lymphoid tissue - MALT) и, в частности, функциональной активности IgA-продуцентов. В слизистых оболочках мыши и человека сосредоточено > $80 \%$ всех плазматических клеток организма [46]. Наиболее изучены лимфоидные ткани кишечника (Gut associated lymphoid tissue - GALT). Основными элементами GALT являются Пейеровы бляшки, мезентериальные лимфатические узлы, lamina propria и отдельные лимфоидные фолликулы. В слизистой оболочке кишечника представлены как лимфоциты 
В-1, так и В-2. При этом В-1 лимфоциты локализованы преимущественно в lamina propria, а В-2 - в Пейеровых бляшках, лимфатических узлах и отдельных фолликулах. Наивные B-2-клетки попадают в GALT из кровотока через высокоэндотелиальные венулы в Пейеровых бляшках и мезентериальных лимфатических узлах. Другой источник мукозальных В-лимфоцитов - перитонеальная полость. Около 40-50 \% IgA-продуцентов кишечника берут начало от B-1aпредшественников из брюшной полости [47]. Кроме того, как уже упоминалось, микроокружение брюшной полости коммитирует В-лимфоциты к миграции в лимфоидные ткани кишечника (в частности, на В-клетках усиливается экспрессия $\beta 7$-интегринов).

Основная отличительная особенность мукозальных В-клеток - образование IgA, которые продуцируют как В-1, так и В-2. В сыворотке крови IgA присутствует в виде мономера, а в секретах - в форме димера (значительно реже - в виде полимера); он называется секреторным IgA (sIgA). Димер IgA coдержит Ј-цепь, соединяющую мономерные молекулы, и секреторный компонент. Функции sIgA многообразны и изучены не до конца: основная его роль взаимодействие с поверхностью микроорганизмов и предотвращение их прикрепления к слизистой оболочке с последующей ее колонизацией. Кроме того, есть данные о том, что IgA необходим для нормального существования комменсальных бактерий в кишечнике.

Для переключения изотипа продуцируемых $\mathrm{Ig}$ c IgM на IgA В-лимфоциты должны получить дополнительные активационные сигналы от $\mathrm{CD}^{+}$ T-хелперов. Образование IgA лимфоцитами В-2, как правило, вопросов не вызывает, поскольку они получают "классическую" МНС-рестриктированную Т-клеточную помощь и дифференцируются в зародышевых центрах. Однако, каким образом претерпевают смену изотипа В-1-клетки, специфичные к Th-антигенам и, соответственно, не получающие дополнительного сигнала от CD4+ T-хелперов, неизвестно. Возможно, в этом случае поступает помощь от "неклассических" $\gamma \delta$ Т-лимфоцитов слизистой оболочки, способных распознавать небелковые антигены. Важно, что такое распознавание не рестриктировано по МНС. Кроме того, клетки, несущие IgA, обнаруживают в брюшной полости [48]. Однако неизвестно, являются они индуцированными, конститутивными или же они мигрировали в брюшную полость уже после смены изотипа. Возникает вопрос, нужно ли перитонеальным В-1-клеткам для смены изотипа на IgA распознавание специфического антигена.

К сожалению, данные о функциональной активности В-лимфоцитов лимфоидных тканей слизистой оболочки респираторного тракта и плевральной полости практически отсутствуют. Однако прослеживается аналогия плевральной полости с перитонеальной: обе они граничат с органами, принимающими на себя наибольшую инфекционную нагрузку; в плевральной и перитонеальной полостях представлены клетки 1-й линии защиты - B-1-лимфоциты.
В связи с этим можно предположить, что иммунная защита слизистой оболочки респираторного тракта реализуется аналогично мукозальной защите кишечника. Очевидно, что функциональная активность плевральных В-клеток в настоящее время требует пристального изучения.

\section{Заключение}

Микроокружение оказывает существенное влияние на функциональную активность В-лимфоцитов. Так, В-клетки слизистых оболочек являются основными продуцентами IgM и IgA мукозальных секретов и обеспечивают защиту слизистых оболочек - основных "ворот" для проникновения патогенов в организм. В-лимфоциты селезенки и лимфатических узлов активно участвуют в формировании пула $\mathrm{IgG}$ и IgM крови и обеспечивают элиминацию чужеродных агентов, проникших внутрь организма. В-лимфоциты в брюшной полости (и, вероятно, плевральной) находятся в "угнетенном" состоянии, являясь при этом источником эффекторных В-лимфоцитов как селезенки, так и лимфоидных тканей слизистых оболочек.

Очевидно, что в этой области множество вопросов остаются нерешенными. Для чего и за счет каких механизмов угнетается активность В-лимфоцитов брюшной полости? Подавляется ли синтез Ig или их секреция? Каким образом неактивные перитонеальные В-клетки получают сигнал, чтобы покинуть брюшную полость? Какова природа сигналов, индуцирующих миграцию перитонеальных В-лимфоцитов в эффекторные? Как происходит смена изотипа c IgM на IgA у B-1-клеток? Требуется ли для этого распознавание специфического антигена? Каковы свойства В-лимфоцитов плевральной полости и их роль в мукозальной защите респираторного тракта? Есть ли В-1-клетки в еще одной полости тела - перикардиальной - и какова их роль?

Изучение свойств В-лимфоцитов разной локализации - важная иммунологическая задача. Понимание процессов, реализуемых в различном микроокружении и активирующих либо угнетающих активность В-клеток, необходимо для дальнейшего совершенствования средств иммунопрофилактики и создания лекарственных препаратов. Особенно актуальной в последнее время стала проблема защиты слизистых оболочек пищеварительного и респираторного трактов, а следовательно (поскольку В-клетки вносят существенный вклад в ее формирование), и функциональной активности перитонеальных и плевральных В-лимфоцитов.

\section{Литература}

1. Murphy K., Travers P., Walport M. et al. Janeway's immunobiology. $7^{\text {th }}$ ed. New York; London: Garland science; 2008.

2. Сидорова E.B. Что нам известно сегодня о В-клетках. Успехи соврем. биол. 2006; 3: 227-241.

3. Caligaris-Cappio F., Gobbi M., Bofill M. et al. Infrequent normal B lymphocytes express features of B-chronic lymphocytic leukemia. J. Exp. Med. 1982; 155: 623-628. 
4. Hayakawa K., Hardy R.R., Parks D.R. et al. The "Ly-1 B" cell subpopulation in normal immunodefective, and autoimmune mice. J. Exp. Med. 1983; 157 (1): 202-218.

5. Casali P., Burastero S.E., Nakamura M. et al. Human lymphocytes making rheumatoid factor and antibody to ssDNA belong to Leu-1+ B cell subset. Science 1987; 236: 77-81.

6. Dauphinee M., Tovar Z., Talal N. B cells expressing CD5 are increased in Sjogren's syndrome. Arthr. and Rheum. 1988; 31: 642-647.

7. Hardy R.R., Hayakawa K., Shimizu M. et al. Rheumatoid factor secretion from human Leu-1 B cells. Science 1987; 236: 81-83.

8. Masmoudi H., Mota-Santos T., Huetz F. et al. All T15 Id-positive antibodies (but not the majority of VHT15 antibodies) are produced by peritoneal $\mathrm{CD}^{+} \mathrm{B}$ lymphocytes. Int. Immunol. 1990; 2: 515-520.

9. Kantor $A$. $A$ new nomenclature for B cells. Immunol. Today 1991; 12: 388.

10. Stall A.M., Adams S., Herzenberg L.A. et al. Characteristics and development of the murine B-1b (Ly-1 B sister) cell population. Ann. N. Y. Acad. Sci. 1992; 651: 33-43.

11. Pospisil R., Mage R.G. CD5 and other superantigens as 'ticklers' of the B-cell receptor. Immunol. Today 1998; 19 (3): 106-108.

12. Thiriot A., Drapier A.M., Vieira P. et al. The Bw cells, a novel B cell population conserved in the whole genus Mus. J. Immunol. 2007; 179 (10): 6568-6578.

13. Hardy R.R., Hayakawa K. A developmental switch in B lymphopoiesis. Proc. Natl. Acad. Sci. USA 1991; 88: $11550-11554$.

14. Сидорова Е.В. Субпопуляции В лимфоцитов и их функциональная роль. Успехи соврем. биол. 2002; 122 (5): 467-479.

15. Cong Y.Z., Rabin E., Wortis H.H. Treatment of murine $\mathrm{CD}^{-} \mathrm{B}$ cells with anti-Ig, but not LPS, induces surface CD5: two B cell activation pathways. Int. Immunol. 1991; 3: 467-476.

16. Lam K.P., Rajewsky K. B cell antigen receptor specificity and surface density together determine B-1 versus B-2 cell development. J. Exp. Med. 1999; 190; 471-477.

17. Montecino-Rodriguez E., Leathers H., Dorshkind K. Identification of a B-1 B cell-specified progenitor. Nat. Immunol. 2006; 7 (3): 293-301.

18. Tung J.W., Mrazek M.D., Yang Y. et al. Phenotypically distinct B cell development pathways map to the three B cell lineages in the mouse. Proc. Natl. Acad. Sci. USA 2006; 103 (16): 6293-6298.

19. Pinho Mde F., Hurtado S.P., El-Cheikh M.C. et al. Haemopoietic progenitors in the adult mouse omentum: permanent production of B lymphocytes and monocytes. Cell Tissue Res. 2005; 319 (1): 91-102.

20. Düber S., Hafner M., Krey M. et al. Induction of B-cell development in adult mice reveals the ability of bone marrow to produce B-1a cells. Blood 2009; 114 (24): 4960-4967.

21. Esplin B.L., Welner R.S., Zhang Q. et al. A differentiation pathway for B1 cells in adult bone marrow. Proc. Natl. Acad. Sci. USA 2009; 106 (14): 5773-5778.

22. Lortan J., Gray D., Kumararatne D.S. et al. Regulation of the size of the recirculating B cell pool of adult rats. Adv. Exp. Med. Biol. 1985; 186: 593-601.

23. Martin F., Kearney J.F. Marginal zone B cells. Nat. Rev. Immunol. 2002; 2: 323-335.

24. Kumararatne D.S., Gagnon R.F., Smart Y. Selective loss of large lymphocytes from the marginal zone of the white pulp in rat spleens following a single dose of cyclophosphamide. A study using quantitative histological methods. Immunology 1980; 40: 123-131.

25. Hardy R.R. B-1 B cell development. J. Immunol. 2006; 177 (5): 2749-2754.

26. Brandtzaeg P, Johansen F.E. Mucosal B cells: phenotypic characteristics, transcriptional regulation, and homing properties. Immunol. Rev. 2005; 206: 32-63.

27. Fujihashi K., McGhee J.R., Yamamoto M. et al. Role of gamma delta $\mathrm{T}$ cells in the regulation of mucosal IgA response and oral tolerance. Ann. N. Y. Acad. Sci. 1996; 778: 55-63.

28. Moser B., Eberl M. $\gamma \delta \mathrm{T}$ cells: novel initiators of adaptive immunity. Immunol. Rev. 2007; 215: 89-102.

29. Guinamard R., Okigaki M., Schlessinger J. et al. Absence of marginal zone B cells in Pyk-2-deficient mice defines their role in the humoral response. Nat. Immunol. 2000; 1; 31-36.

30. Wells S.M., Kantor A.B., Stall A.M. CD43 (S7) expression identifies peripheral B cell subsets. J. Immunol. 1994; 153 (12): 5503-5515.

31. Hastings W.D., Gurdak S.M., Tumang J.R. et al. $\mathrm{CD}^{+} /$ Mac-1-peritoneal B cells: a novel B cell subset that exhibits characteristics of B-1 cells. Immunol. Lett. 2006; 105 (1): 90-96.

32. Chumley M.J., Dal Porto J.M., Cambier J.C. The unique antigen receptor signaling phenotype of B-1 cells is influenced by locale but induced by antigen. J. Immunol. 2002; 169 (4); 1735-1743.

33. Tumang J.R., Hastings W.D., Bai C. et al. Peritoneal and splenic B-1 cells are separable by phenotypic, functional, and transcriptomic characteristics. Eur. J. Immunol. 2004; 34 (8): 2158-2167.

34. Ansel K.M., Harris R.B., Cyster J.G. CXCL13 is required for B1 cell homing, natural antibody production, and body cavity immunity. Immunity 2002; 16; 67-76.

35. Fischer G.M., Solt L.A., Hastings W.D. et al. Splenic and peritoneal B-1 cells differ in terms of transcriptional and proliferative features that separate peritoneal B-1 from splenic B2 cells. Cell. Immunol. 2001; 213; 62-71.

36. Ohdan H., Swenson K.G., Kruger Gray H.S. et al. Mac-1negative B-1b phenotype of natural antibody-producing cells, including those responding to $\mathrm{Gal}$ alpha 1,3 Gal epitopes in alpha 1,3-galactosyltransferase-deficient mice. J. Immunol. 2000; 165 (10): 5518-5529.

37. Kretschmer K., Jungebloud A., Stopkowicz J. et al. Antibody repertoire and gene expression profile: Implications for different developmental and functional traits of splenic and peritoneal B-1 lymphocytes. J. Immunol. 2003; 171: 1192-1201.

38. Prior L., Pierson S., Woodland R.T. et al. Rapid restoration of B-cell function in XID mice by intravenous transfer of peritoneal cavity B cells. Immunology 1994; 83: 180-183.

39. Дьяков И.Н., Гаврилова М.В., Чернышова И.Н. и др. Влияние микроокружения на функциональную активность В-лимфоцитов мыши. Биол. мембраны 2008; 25 (5): 360-366.

40. Дьяков И.Н., Григорьев И.В., Сидорова Е.В. и др. Функциональная активность В-клеток мыши. Роль микроокружения. Мед. иммунол. 2008; 10 (1): 51-58.

41. Hastings W.D., Tumang J.R., Behrens T.W. et al. Peritoneal B-2 cells comprise a distinct B-2 cell population with B-1blike characteristics. Eur. J. Immunol. 2006; 36 (5): 1114-1123.

42. Berenson C.S., Ryan J.L. Murine peritoneal macrophage gangliosides inhibit lymphocyte proliferation. J. Leukoc. Biol. 1991; 50 (4): 393-401. 
43. Chace J.H., Fleming A.L., Gordon J.A. et al. Regulation of differentiation of peritoneal B-1a $\left(\mathrm{CD}^{+}\right) \mathrm{B}$ cells. Activated peritoneal macrophages release prostaglandin $\mathrm{E} 2$, which inhibits IgM secretion by peritoneal B-1a cells. J. Immunol. 1995; 154 (11): 5630-5636.

44. Tanaka F., Tominaga K., Shiota M. et al. Interleukin-10 gene transfer to peritoneal mesothelial cells suppresses peritoneal dissemination of gastric cancer cells due to a persistently high concentration in the peritoneal cavity. Cancer Gene Ther. 2008; 15 (1): 51-59.

45. Popi A.F., Lopes J.D., Mariano M. Interleukin-10 secreted by B-1 cells modulates the phagocytic activity of murine macrophages in vitro. Immunology 2004; 113 (3): 348-354.

46. Brandtzaeg P., Farstad I.N., Johansen F-E. et al. The B-cell system of human mucosae and exocrine glands. Immunol. Rev. 1999; 171: 45-87.
47. Kroese F.G., Butcher E.C., Stall A.M. et al. Many of the IgA producing plasma cells in murine gut are derived from selfreplenishing precursors in the peritoneal cavity. Int. Immunol. 1989; 1: 75-84.

48. Roy B., Shukla S., Łyszkiewicz M. et al. Somatic hypermutation in peritoneal B1b cells. Mol. Immunol. 2009; 46 (8-9): 1613-1619.

\section{Информация об авторах}

Дьяков Илья Николаевич - к. б. н., научный сотрудник лаборатории биосинтеза иммуноглобулинов НИИ вакцин и сывороток им. И.И.Мечникова РАМН; тел.: (495) 674-08-42; e-mail: dyakov.ilya@gmail.com

Сидорова Екатерина Владимировна - д. б. н., проф., зав. лабораторией биосинтеза иммуноглобулинов НИИ вакцин и сывороток им. И.И.Мечникова РАМН; тел.: (495) 674-08-42; e-mail: sidorova99 @hotmail.com

Поступила 04.03.10

(с Дьяков И.Н., Сидорова Е.В., 2010 